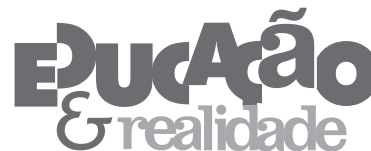

\section{Ciência e Ideologia na Prática dos Professores de Sociologia no Ensino Médio: da neutralidade impossível ao engajamento indesejável, ou seria o inverso?}

\author{
Amaury Cesar de Moraes' \\ 'Universidade de São Paulo (USP), São Paulo/SP - Brasil
}

RESUMO - Ciência e Ideologia na Prática dos Professores de Sociologia no Ensino Médio: da neutralidade impossível ao engajamento indesejável, ou seria o inverso? O impacto que a inclusão da sociologia nos currículos do ensino médio causou no âmbito da escola e no campo das ciências sociais tem sido avaliado sob diferentes perspectivas: a) para uma, há perigo de que a sociologia não seja ensinada como ciência, mas como discurso ideológico; b) para outra, o ensino de Sociologia deve ser conscientizador e transformador da sociedade; c) uma terceira enfatiza seu caráter de alfabetização científica, ao equipar estudantes com teorias e métodos, levando-os à consciência de si mesmos e do mundo em que vivem. Pensando a escola média como espaço público, a escolha por uma das vertentes vai além das convicções pessoais do professor, sendo norteada por sua responsabilidade como formador de cidadãos autônomos.

Palavras-chave: Ensino de Sociologia. Ideologia. Imprensa. Alfabetização Científica.

ABSTRACT-Science and Ideology in Teachers' Practice of Sociology in High School: from the impossible neutrality to the undesirable engagement, or is it the other way around? The impact that the inclusion of sociology in high school curriculums caused within the school and in the social sciences has been evaluated from different perspectives: a) for, there is danger that sociology is not taught as science, but as a discourse ideological b) to another, the teaching of sociology should be conscientizing and transforming society, c) a third, emphasizes its character of scientific literacy in equipping students with theories and methods, leading them to the awareness of themselves and the world they live. Thinking middle school as a public space, the choice of one element goes beyond the personal convictions of the teacher, being guided by his responsibility as forming autonomous citizens.

Keywords: Teaching Sociology. Ideology. Press. Scientific Literacy.

Educação \& Realidade, Porto Alegre, v. 39, n. 1, p. 17-38, jan./mar. 2014

Disponível em: <http://www.ufrgs.br/edu_realidade> 


\title{
Introdução
}

\begin{abstract}
P - O prof. Fernando de Azevedo dizia que nos primeiros anos da Faculdade (de Filosofia da USP) era muito comum, em São Paulo, a confusão entre sociologia e socialismo.

Ruy Coelho - A equipe que fez a primeira pesquisa da Faculdade, sobre os lixeiros de São Paulo, foi toda presa, mas libertada logo depois, ou seja, havia a ideia de que pesquisar assuntos como esse era "coisa perigosa". Não havia uma ideia muito clara do que fosse a Sociologia, e por isso ela era encarada a priori como algo que cheirava enxofre (Bastide; Coelho, 1979, p. 180).
\end{abstract}

Neste ensaio, pretendo refletir, a partir de três fontes bastante distintas, sobre a presença do ensino de sociologia na escola média brasileira: é algo que deva buscar uma neutralidade científica ou deva ceder ao engajamento político? Ou haveria uma terceira via, ainda assim crítica? Uma das fontes pode ser bastante questionada quanto à sua legitimidade heurística, mas não pudemos contorná-la em vista de sua autoimputada importância como "formadora de opinião": a imprensa. As outras duas, embora em níveis diferentes, são de mesma natureza acadêmica: textos clássicos do campo da sociologia e textos de alunos de cursos de especialização e de graduação em Ciências Sociais. Encontramo-nos, pois, entre estes extremos e recorremos ainda uma vez aos clássicos como forma de nos garantir, senão uma legitimidade maior - que as outras duas fontes se arrogam - ao menos aquela segurança intelectual e aquela tranquilidade pessoal para podermos dormir sem desassossego.

Entendendo a escola pública ainda como espaço de transição para o mundo político, visto que se situa entre a família - âmbito privado por excelência - e a sociedade civil - esfera caracteristicamente política -, e o professor como agente público a quem cabe a formação de crianças e jovens (Arendt, 2007), as escolhas feitas por esse devem ser norteadas pela responsabilidade, superando em sala de aula as suas convicções pessoais em favor da construção da autonomia dos alunos (Weber, 1983).

\section{Imprensa: de quarto poder a central de triagem ideológica}

Faz parte das fontes deste ensaio um conjunto de artigos publicados na mídia, impressa ou eletrônica - os tais blogs - que, como costuma dizer a própria imprensa, "repercutiram" a notícia da aprovação pelo Congresso Nacional e sanção do Presidente da República em exercício da alteração da LDB, no que se refere à obrigatoriedade do ensino de Sociologia e Filosofia na escola média brasileira (Lei 11.684/2008). São eles: Nelson Ascher, Doutrinação Barata, Folha de S. Paulo, 9 jun. 2008; Reinaldo Azevedo, Cuidem de suas Crianças! Os Molestadores Ideológicos Vêm Aí, Blog da Veja.com, 3 jun. 2008; Gustavo Ioschpe, Errar é 
Humanas, seção Educação da Veja.com, 30 jun. 2008; Hélio Schwartsman, A Volta da Filosofia, Folha Online, 12 jun. 2008; Roberto Macedo, Sociologia \& Cia. no CNE \& Cia, O Estado de S. Paulo, 20 jul. 2006. Este artigo de Roberto Macedo foi incluído porque tratou da questão sob a mesma perspectiva dos outros quando a obrigatoriedade das disciplinas foi introduzida pelo Conselho Nacional da Educação, em 2006 (CNE/CEB Parecer 38/2006), o que não foi aceito por uma das unidades da federação (o Conselho Estadual de Educação de São Paulo) e acabou levando o debate ao Congresso Nacional, de onde resultou a referida alteração da LDB.

De um modo geral, os artigos repetem certas características básicas ou certos temas a partir dos quais se justifica a principal razão por que são escritos: a crítica ao caráter ideológico do ensino de Sociologia e Filosofia. Alguns como Ascher (2008) e Ioschpe (2008) apresentam primeiramente suas concepções de educação: para Ascher, a escola não tem o menor sentido a não ser fazer passar nos exames vestibulares, pois tudo que nela se aprende se esquece: "Cada qual de nós preserva em si aquilo que o atrai, emociona, interessa". Ioschpe tem uma posição bem diversa, supervalorizando o que é aprendido na escola, desde que seja pelo método correto, por exemplo: "[...] o nosso ensino é tão fraco. No Brasil, não se ensina matemática. Se ensina a resolução de problemas matemáticos. Nossas escolas explicam a mecânica da coisa". Aliás, essa referência à matemática não vem ao caso, uma vez que, para o autor, "hoje vejo que a matéria mais importante é estatística" ou "E se fosse para incluir uma nova disciplina em nosso currículo, adoraria que fosse estatística". Ioschpe ainda se arrisca como um leitor de Platão, ao dizer: "Agora vejo que a estatística é a base de tudo, é o que possibilita a distinção entre a opinião e o fato, a aparência e a realidade (as 'formas' platônicas)". Mas nesse caso Platão seria o culpado, pois, como diz a lenda, ele teria escrito no pórtico da Academia: "Não entre aqui quem não for geômetra".

Um ponto forte nas críticas à obrigatoriedade do ensino de Sociologia e Filosofia se prende ao diagnóstico que todos os jornalistas fazem sobre a educação no Brasil. Todos são concordes com a situação precária da nossa educação básica e entendem que as disciplinas ora incluídas no currículo não só não contribuirão para a melhoria, como ainda poderão ser nocivas diante dessa situação, além de elas mesmas encontrarem dificuldades para sua efetivação, pois todos apontam para as dificuldades principais ligadas a conhecimentos de Matemática e de Língua Portuguesa:

[...] o nosso ensino é tão fraco [...] Veja só: nosso sistema educacional é um fracasso tão retumbante que, na última medição em que o desempenho dos alunos foi dividido em níveis, o SAEB de 2003 apontou que $55 \%$ dos alunos da quarta série estavam em situação crítica ou muito crítica em leitura, o que quer dizer que eram praticamen-

Educação \& Realidade, Porto Alegre, v. 39, n. 1, p. 17-38, jan./mar. 2014.

Disponível em: <http://www.ufrgs.br/edu_realidade> 
Ciência e Ideologia na Prática dos Professores de Sociologia no Ensino Médio

te analfabetos. A maioria dos alunos que faz a prova de Matemática no SAEB acha que ' $3 / 4$ ' é 3,4 , e não 0,75 . Não entendem nem a notação de uma fração. Achar que esses professores, com essa qualidade, conseguirão ensinar filosofia e sociologia a esses alunos é o que os ingleses chamam de wishful thinking, um otimismo despropositado (Ioschpe, 2008, s.p.).

Para que, num país que mal ensina (e ensina mal) coisas fundamentais como matemática, escrita e leitura, acrescentar essa sobrecarga que, além de inútil e irrelevante, nem as escolas privadas e muito menos as públicas terão condições de ensinar decentemente? (Ascher, 2008, p. E6).

São também matérias abstratas, que exigem grande volume de leitura, e difíceis de ensinar e aprender, particularmente no caso de educandos que têm grandes dificuldades no domínio da linguagem, seja para ler e compreendê-la, seja para responder a exames orais ou escritos (Macedo, 2006, p. 2).

Exames internacionais de matemática e entendimento de texto demonstram que o ensino brasileiro é uma tragédia. Filosofia e sociologia vão ajudar em quê? Em nada. [...] Ao lado da eterna reclamação dos professores de que faltam condições de trabalho nas escolas, o que, no geral, é mentira, a tal "educação crítica", de que fala o ministro, responde por boa parte da miséria do país nessa área. Se o ensino de matemática - e das ciências - é uma lástima, o das disciplinas abrigadas na rubrica "Humanidades" costuma ser uma insanidade... (Azevedo, 2008, s.p.).

Apenas Schwartsman tenta uma explicação histórica dessa realidade, mas que conduz a uma situação sem saída, marcada pela "proletarização do professorado":

Entre os anos 30 - a era dourada do ensino público - e os 90, o número de alunos da rede oficial aumentou nada menos do que 20 vezes. Os recursos aplicados cresceram numa proporção bem menor. O resultado foi duplamente perverso. De um lado, a incorporação de grandes contingentes de alunos do estrato social mais baixo significou uma queda na qualidade. Esse, entretanto, era um efeito esperado e que deveria ser transitório. De outro, a rápida ampliação da rede sem um aumento correspondente dos recursos investidos levou a uma espécie de proletarização do professorado (Schwartsman, 2008, s.p.).

Talvez o texto de Schwartsman seja o que procura enfrentar a questão de um modo um tanto mais cuidadoso ou mais fundamentado, porque o autor começa apresentando-se como de formação filosófica e questiona, de certa forma, as razões que a assim chamada por ele "direita" apresenta: "A turma da direita já saiu gritando que o novo diploma vai institucionalizar a doutrinação esquerdista. É um risco, admito”. O 
autor tenta demonstrar que a crise da educação não se resolverá com a introdução de Filosofia e Sociologia: "Meu propósito central nesta coluna é mostrar que a volta da filosofia e da sociologia ao ciclo básico não passa nem perto de ser uma solução para a grave crise que a educação enfrenta hoje" (Schwartsman, 2008, s.p.).

Mas os autores ainda esgrimem outros argumentos. Como a filiação da proposta diretamente ao PT e, no texto de Azevedo (2008, s.p.), a uma futura candidatura do Ministro da Educação, Fernando Haddad:

\begin{abstract}
'O que se vê é que, evidentemente, nos períodos em que não interessava a discussão crítica sobre a vida nacional, estas disciplinas foram desestimuladas', afirmou ontem o ministro da Educação, Fernando Haddad, que será, aposto, o candidato do PT à Presidência em 2010. Mas isso ainda não é o mais preocupante. A fala de Haddad, capaz de escrever monstruosidades em seus livros, já dá a pista do que vem por aí.
\end{abstract}

Ou problemas de custeio, em escolas públicas e privadas, e falta de professores são apontados por Macedo (2006, p. 2): “Ademais, o CNE deveria ter ponderado as necessidades de recursos nas escolas particulares e públicas, que serão obrigadas a contratar novos professores para tais disciplinas”. Ascher (2008, p. E6) segue uma linha semelhante:

Naturalmente essas disciplinas não serão minimamente bem ensinadas e todo mundo sabe disso. Não há quadros, não há tempo, não há verbas e, sobretudo, não há nem haverá interesse algum por parte das vítimas potenciais, os alunos. [...] Onde é que vão se recrutar bons professores de filosofia e sociologia?

O argumento de Azevedo (2008, s.p.) junta-se aos anteriores: "Escolas particulares de primeiro time darão um jeito de ampliar a carga - e, se preciso, elevarão o preço das mensalidades. [...] Cadê os professores?".

Estes argumentos foram aludidos nas justificativas que o presidente Fernando Henrique Cardoso apresentou em 2001 para vetar o Projeto de Lei 09/2000, de autoria do deputado Padre Roque Zimmermann, a que chamei noutro lugar de "as razões do veto" (Moraes, 2004), mas que são muito frágeis quando se pensa objetivamente a questão: estas disciplinas já fizeram parte do currículo, Filosofia desde a chegada de Tomé de Souza e os jesuítas no Brasil, Sociologia desde fins do século XIX até 1942, quase desaparecendo do currículo do colegial com a reforma Capanema, retornando depois a partir dos anos $1980 \mathrm{com}$ a redemocratização do país. De modo que o seu espaço no currículo foi ocupado pelas outras disciplinas, que agora poderiam devolver-lhes o lugar, não havendo necessidade de ampliar a carga, e, portanto, de recursos extras nas instituições públicas ou de se elevar o preço das mensalidades nas escolas privadas; se bem que poderia ser oportunidade

Educação \& Realidade, Porto Alegre, v. 39, n. 1, p. 17-38, jan./mar. 2014 21 
Ciência e Ideologia na Prática dos Professores de Sociologia no Ensino Médio

de se implantar a tão esperada escola integral no Brasil. De outra parte, a falta de professores é um argumento discutível, porque nesses anos todos os egressos de cursos de Filosofia e Sociologia têm se desviado do rumo do magistério e ido trabalhar em outras profissões, constituindo um verdadeiro exército de reserva, que quando se abrem concursos para estas disciplinas, sempre o número de candidatos é muito superior ao de vagas; e temos visto divulgados pela mídia dados referentes à ausência ou dificuldades de recrutamento de professores de Física, Química, Geografia e Língua Portuguesa, sem, contudo que se proponha a exclusão dessas disciplinas. Do mesmo modo, a qualidade dos professores de Filosofia e Sociologia certamente não destoaria, nem para melhor nem para pior, da qualidade do conjunto dos professores em geral, pois são formados nas mesmas instituições superiores que os demais, não vindo a constituir um perigo maior se fosse esse o critério. Os bons professores de Filosofia e Sociologia poderiam ser recrutados do mesmo modo que os bons professores das outras disciplinas.

Tudo, no entanto, serve de pano de fundo, em que o estilo dos autores vai das pretensões crítico-literárias de um Nelson Ascher e suas eruditas e aristocráticas lembranças sobre o esquecimento de um personagem de Dostoievski, ao texto pretensamente filosófico e neutro de Hélio Schwartsman, que quer fugir aos argumentos de esquerda e de direita, passando pelo iracundo antipetismo de Reinaldo Azevedo e o maldisfarçado anti-humanidades matematicófilo de Gustavo Ioschpe ou o explicitamente antissociologia Roberto Macedo. Tudo serve como argumento para o que realmente se pretende: denunciar o ensino de Sociologia e Filosofia como pura e simples doutrinação - aliás, mais do que isso: uma verdadeira armação para que o marxismo seja ensinado nas escolas. Assim aparece essa variação sobre o mesmo tema ou argumento:

A resposta se torna evidente quando ouvimos autoridades e os interessados confessando, sem querer, seu objetivo real. Eles falam em encorajar a visão ou pensamento crítico. Essa expressão nojenta oculta, ou melhor, revela o ápice da arrogância: nossa maneira de pensar, que chamamos mentirosamente de 'crítica', é a certa, a única certa. [...] Como hoje controlamos a lei, nós a usaremos para impor nossos dogmas aos adolescentes, impedindo-os de pensarem por conta própria. Para que perder tempo com tentativa e erro se já temos todas as respostas? Enfim, sociologia e filosofia no ensino médio são apenas eufemismos. Seu nome verdadeiro é doutrinação barata (Ascher, 2008, p. E6).

O que acho da medida. Uma porcaria! O Brasil acha que ensinar a fazer conta é coisa muito complicada; não é mesmo para nós. O nosso negócio, como é mesmo?, é ensinar a pensar, entenderam? A 'refletir criticamente sobre a nossa realidade', para que se formem, então, 'cidadãos conscientes'. Puro lixo retórico e ideológico. Para seguir 
a lei, professores de outras disciplinas terão de ser improvisados nas aulas de filosofia e sociologia. Mal posso esperar pelo material didático. O 'filósofo' vai ministrar história do pensamento? Duvido! As aulas se perderão em grandes debates - de preferência, em círculo - sobre os dilemas 'éticos' de nossa realidade. Os alunos continuarão com alguma dificuldade para dizer quanto é sete vezes nove, mas serão estimulados a fazer sempre 'colocações' muito inteligentes. [...] Estamos fritos! Cuidem de suas crianças. Vai começar o período do molestamento ideológico explícito (Azevedo, 2008, s.p.).

É impossível estudar filosofia se você não sabe ler. Essas aulas serão apenas uma maneira mais escancarada de se praticar o doutrinamento do marxismo rastaquera que impera em nossas escolas (Ioschpe, 2008, s.p.).

Schwartsman (2008, s.p.) inova no argumento, sugerindo-o de modo oblíquo:

O regime militar foi criticado, com razão, por ter eliminado, em 1971, as duas disciplinas do então colegial. Fê-lo por razões muito mais pragmáticas do que teóricas: essas matérias agregavam um número desproporcionalmente grande de professores com ideias de esquerda.

Schwartsman traz um argumento que coincide com aquele de um de seus mestres na Universidade de São Paulo, Prof. José Arthur Giannotti, e que aconselhara ao presidente Fernando Henrique Cardoso por ocasião do veto a medida semelhante:

Mas há também um outro que eles não apontam: como as faculdades de filosofia dificilmente serão capazes de fornecer a legião de professores necessária para suprir a demanda, as escolas tenderão a recrutar seus docentes pela habilitação mais próxima da filosofia, que é a teologia. E se há algo tão ruim quanto um exército de marxistas vulgares armados de discursos anti-imperialistas é uma hoste de padres brandindo catecismos. Pior mesmo só se forem clérigos disparando teologia da libertação, que junta as mais capengas categorias do marxismo ao mais caricatural reacionarismo católico, mas deixemos esse cenário apocalíptico de lado (Schwartsman, 2008, s.p.).

Todos esses casos anteriores não revelam senão um preconceito, impressões genéricas sobre as humanidades, como acontece com Azevedo, ao dizer que

[...] o que é comprovado por um exame simples dos livros didáticos de história e geografia, por exemplo: perdem-se no mais estúpido proselitismo, pautados por um submarxismo ignorante e bolorento. Já demonstrei aqui de que monstruosidades é capaz um professor de história de um cursinho, mesmo tendo de seguir uma apostila (2008, s.p.).

Educação \& Realidade, Porto Alegre, v. 39, n. 1, p. 17-38, jan./mar. 2014

Disponível em: <http://www.ufrgs.br/edu_realidade> 
Ciência e Ideologia na Prática dos Professores de Sociologia no Ensino Médio Macedo:

O que mais impressiona é a argumentação ex-cathedra de Roberto

Se ela pegar, e quanto ao que será ensinado aos alunos, vou limitar-me à Sociologia. Pelas suas maiores afinidades com a Economia, conheço mais sociólogos que filósofos e sei que a maior parte da Sociologia brasileira, em particular a ministrada nos cursos superiores de graduação que formam professores para os níveis anteriores, é dominada por um forte viés ideológico que privilegia a visão marxista de guerra de classes. É uma formação dogmática que se limita a tomar como verdadeiras as afirmações do evangelho de Marx e a sair por aí a interpretar fatos conforme essa visão. Não há a preocupação científica de tomá-las apenas como hipóteses entre outras e de confrontar o conjunto delas com os fatos, examinando-se dados da realidade com rigor metodológico (2006, p. 2).

O que temos então dos formadores de opinião? Primeiro, não são formadores de opinião, são transmissores de opinião porque mal e mal conseguem articular uma argumentação em defesa de seus pontos de vista; segundo, cada um traz preconceitos advindos de informações muito gerais ou de sua própria biografia - como Azevedo, como Ascher, como Schwartsman, e mesmo como Macedo; Ioschpe mistura ainda mais sua biografia - sua formação - com sua argumentação e se perde em contradições, além de revelar um cartesianismo bastante mal digerido:

No Brasil, não se ensina matemática. Se ensina a resolução de problemas matemáticos. [...] a matemática é a árvore da qual brotam os frutos das ciências exatas: física, química, biologia, estatística, engenharia, medicina - nada disso seria possível sem a matemática. [...] Eu só fui descobrir isso quando já estava no mestrado (Ioschpe, 2008, s.p.).

Seus argumentos são contraditórios porque, segundo a Wikipédia, Ioschpe "[...] estudou em escolas particulares e graduou-se no exterior” e só foi descobrir a importância da matemática no mestrado, tendo feito duas graduações nos Estados Unidos - ou seja, não é só no Brasil que essas mazelas acontecem. Por outro lado, que dados empíricos ele tem para dizer que "É impossível estudar filosofia se você não sabe ler. Essas aulas serão apenas uma maneira mais escancarada de se praticar o doutrinamento do marxismo rastaquera que impera em nossas escolas" (2008). Sem dizer que a Matemática não é uma “ciência empírica” e, a confiar no julgamento de Albert Einstein (1921), citado por Felix Kaufmann (1977, p. 56), não é exata: "Na medida em que a matemática se refere à realidade, não é exata, e na medida em que não é exata, não se refere à realidade".

Lendo esses textos todos não há como não se lembrar de Marx, de acordo com Galbraith (A Era da Incerteza), o qual cito de memória: 
Em Roma todos os esgotos eram levados em condutos subterrâneos até um local, a cloaca maxima, onde eram lançados no rio Tibre; em Londres todo lixo, podridão e sujeira produzidos pela burguesia são conduzidos e despejados na cloaca máxima chamada de The Daily Telegraph.

\section{Do Outro Lado da Vara: a ciência a serviço da ideologia}

Caminhando para o outro lado da vara, temos a situação seguinte. Desde que participei como coordenador da equipe do MEC para elaboração das Orientações Curriculares para o Ensino Médio (OCEM) de Sociologia (Brasil, 2006), passamos a receber críticas de vários grupos porque resolvemos nos recusar a apresentar uma proposta única nacional de conteúdos para o ensino da disciplina. O que nos moveu foi entender que as OCEM deveriam ter o papel precípuo de orientar os professores e abrir espaço para que o movimento em defesa da obrigatoriedade do ensino da disciplina no nível médio superasse essa fase de luta, de pressão sobre os agentes públicos de decisão (CNE, Congresso Nacional, MEC e Presidência da República) e se transformasse em um amplo processo de discussão de questões mais cotidianas e voltadas especialmente para professores: conteúdos, métodos, recursos didáticos etc. No entanto as interpretações que o documento suscitou ganharam um caráter político-ideológico, identificando as OCEM-Sociologia como uma proposta de política pública de caráter neoliberal, flexibilizante e mesmo impeditivo de avanços. Das manifestações com esse teor, duas se destacam porque se recobrem da legitimidade acadêmica e uma terceira, ainda que indiretamente, por questionar a criticidade da proposta: um artigo publicado na Revista Mediações, intitulado Pensando a Sociologia no Ensino Médio Através dos PCNEM e das OCNEM, de autoria de Carolina Dias Cunha Casão e Cristiane Thaís Quinteiro, ambas alunas do curso de Especialização em Ensino de Sociologia da UEL e professoras do ensino médio; uma monografia para obtenção do título de bacharel em Ciências Sociais na UEL, de autoria de Eduardo Carvalho Ferreira, intitulada Os Lugares da Sociologia no Ensino Médio: o caso da cidade de Londrina - PR (2007); e uma comunicação apresentada ao IV Encontro Estadual de Didática e Prática de Ensino, Goiás (CEPED-UEG/PUC-GO, 2011), por Larissa Messias Moraes, intitulada Desafios e Propostas da Sociologia no Ensino Médio à luz da Didática para a Pedagogia Histórico-Crítica de João Luiz Gasparin, que, por conta da abordagem, se filia ao grupo da UEL, onde essa pedagogia e esse autor são referências.

No primeiro caso, as autoras fazem uma análise comparativa entre os Parâmetros Curriculares Nacionais do Ensino Médio (PCNEM) e as OCEM, denominadas por elas OCNEM ou OCN, por conta de uma expectativa de que o nome das orientações incorporasse, tal como os parâmetros, a expressão nacionais, o que não veio a acontecer. Ressaltam várias vezes as diferenças, no sentido positivo a favor das OCEM, entre ambos os documentos:

Educação \& Realidade, Porto Alegre, v. 39, n. 1, p. 17-38, jan./mar. 2014.

Disponível em: <http://www.ufrgs.br/edu_realidade> 
Ciência e Ideologia na Prática dos Professores de Sociologia no Ensino Médio

Há um avanço metodológico e político nas OCN, ao simultaneamente defenderem a sociologia como ciência e como disciplina específica ao contrário, os PCN não, eles extrapolam os limites de como tratar a Sociologia, essa passa a ser um instrumento genérico para a construção da cidadania, torna-se um clichê, e como clichê, altamente reproduzido sem reflexão sobre as implicações disso (Casão; Quinteiro, 2007, p. 237).

Entretanto, ao tomar como parti-pris a necessidade de um "currículo nacional comum", as autoras acabam cedendo a uma visão homogeneizadora das propostas:

No caso da Sociologia, uma das dificuldades sentidas até o momento é quanto à sequência dos conteúdos, já que cada escola possui uma autonomia para incluí-la nas séries que desejar. Um dos desafios é pensar num currículo nacional comum e a definição de uma carga horária que seja capaz de contemplar todos os conteúdos. Esse currículo mínimo não aparece de forma categórica nem nos PCN nem nas OCN. Mas pensamos que na defesa da obrigatoriedade, determinada sequência de conteúdos seja importante para justificar o aumento da carga horária. Nesse sentido, as OCN caem também na flexibilidade. E cair na flexibilidade, sem a defesa de um currículo comum pode ser perigoso em termos políticos, correndo o risco de sua diluição em temas transversais. Além disso, dificulta o trabalho dos iniciantes que não têm parâmetros seguros de quais conteúdos privilegiar (Casão; Quinteiro, 2007, p. 236).

O texto indica três consequências da suposta flexibilidade das OCEM: por um lado, o problema da carga horária - sem conteúdos predefinidos, estipulados oficialmente, não se pode "justificar o aumento da carga horária" -, fazendo uma confusão entre a luta pelo ensino de sociologia e aquela pela garantia de mercado para os sociólogos desempregados. Por outro, o risco de o ensino ser diluído em "temas transversais", entendido como "perigoso em termos políticos”, não leva em conta que, se a Sociologia tivesse o seu lugar específico como disciplina do currículo, a questão pedagógica dos temas transversais estaria sepultada, assim como a medida que determinava que a Sociologia tivesse seus conteúdos tratados "de forma contextualizada e interdisciplinarmente” (Parecer CNE/CEB 15/1998 e Resolução CNE/CEB 03/1998). Por fim, os professores iniciantes precisam de "parâmetros seguros de quais conteúdos privilegiar" - isso vai contra a ideia de autonomia do professor, pois todo o debate sobre formação de professores indica que as universidades é que deveriam cuidar de formar seus professores com um mínimo de informações para que pudessem lecionar, e isso inclui capacidade de definir conteúdos, metodologia e recursos com que trabalhar; e que as universidades deveriam entregar esses professores com um capital inicial para exercerem as atividades docentes e, por exemplo, 
pudessem passar num concurso público para o cargo de professor de Sociologia. Nunca houve um conteúdo universalmente aceito e consagrado - o que atribuí à intermitência característica da história da disciplina Sociologia (Moraes, 2003) -, de tal modo que não se pode dizer que houve flexibilização porque não havia o que flexibilizar: cada professor, cada livro didático, cada proposta oficial concebia e concebe um currículo de acordo com sua formação e seu arbítrio. Ao contrário, apresentar mais uma vez uma proposta oficial, e ainda por cima, nacional, representaria um autoritarismo sem precedentes e não livraria quem o fizesse de ser acusado disso, aliás, com toda razão e direito. São estas as palavras com que fizemos a escolha por nos ater a orientações:

Visa-se com esta proposta a evitar os efeitos negativos que poderiam advir da apresentação de um programa ou lista de conteúdos para a disciplina, quer pelo caráter oficial que pudesse assumir e então ser entendido como obrigatório, aceito ou rejeitado por ser oficial, quer pela supressão da liberdade e pelo exercício da criatividade que os professores devem manter e que seriam importantes para a consolidação da disciplina, tendo em vista a variedade de experiências de ensino que pode produzir.

Por esses motivos, esta proposta apresenta-se como mais um passo num processo que, se espera, seja de consolidação definitiva da presença da disciplina no currículo do ensino médio, processo descrito na primeira parte desta exposição, que continua com ela e segue com os próprios professores (Brasil, 2006, p. 131).

Além disso, é bem possível que, para se pensar em proposta nacional que atenda a todos os professores, livros didáticos, características regionais, diretrizes sobre avaliação em larga escala etc., tenha-se que apresentar um conjunto temático definido muito mais por um caráter de transversalidade do que de especificidade da disciplina, caindo uma proposta nacional comum no que as autoras chamam de "perigoso em termos políticos".

A monografia de Ferreira também reconhece as diferenças positivas das OCEM em relação aos PCN:

Nessas Orientações é perceptível uma concepção mais bem acabada da Sociologia e suas possibilidades no Ensino Médio, propõe-se uma problematização entre os papéis que podem ser desempenhados por ela, considerando as particularidades entre a ciência e a disciplina escolar (2007, p. 44).

O autor avalia positivamente também certo estilo mais eficiente das OCEM:

Em termos de construção do texto e de abrangência conceitual, não podemos negar uma melhora qualitativa em relação ao que se tinha, com certeza as Orientações se 
Ciência e Ideologia na Prática dos Professores de Sociologia no Ensino Médio

constituem em um documento com muito mais fluidez, partilhando uma concepção de Sociologia para o Ensino Médio muito mais lapidada (Ferreira, 2007, p. 45).

Mas logo deixa essa positivação e parte para a cobrança de um “posicionamento político", que diz faltar às OCEM:

Mas seu grande problema, a meu ver, é a ausência de um posicionamento político mais bem definido em relação ao sistema educacional, pois em nenhum momento assume-se a Sociologia como um instrumento de crítica e de intervenção nas políticas da educação. Assume-se uma posição muito neutra, até mesmo passiva, em relação às leis que regulamentam a sua própria existência. Entendo que um documento que tem por exigência estabelecer orientações não pode se fechar em um só referencial teórico, mas isso não pode inibi-lo de ter uma postura crítica. Por mais avanços que essas Orientações possam ter representado, soam como algo insosso, pois acrescentam muito pouco no sentido de dar respostas aos professores que buscam aprimorar suas práticas, e ainda, se desenvolve em conformidade com a ordem estabelecida, já que em nenhum momento propõe de fato o exercício de uma Sociologia que seja verdadeiramente contestadora. Seu alcance não vai além da constatação de que a Sociologia tem recursos teóricos para envolver o educando num processo emancipatório, mas não contribui com opções teóricas que realmente confrontam a realidade, no sentido de uma possível transformação em qualquer uma das esferas da sociedade (Ferreira, 2007, p. 45).

A crítica vem pelas expressões "ausência de um posicionamento político", "posição muito neutra, até mesmo passiva", "[necessidade de] ter uma postura crítica", "[as Orientações] soam como algo insosso", "[as Orientações são algo que] se desenvolve em conformidade com a ordem estabelecida", todas a indicar a necessidade do "exercício de uma Sociologia que seja verdadeiramente contestadora". Entendo que isso seja algo que extrapola a responsabilidade do professor, uma vez que este fazer "opções teóricas que realmente confrontam a realidade, no sentido de uma possível transformação em qualquer uma das esferas da sociedade" é retirar dos alunos a condição de uma formação emancipatória e autônoma; além disso, estaríamos fazendo o mesmo com o professor, ao definirmos de um ponto de vista oficial - com toda a força legitimadora que isso possa ter - o que ele deveria ensinar, escolhendo por ele tais "opções teóricas que realmente confrontam a realidade"; assim, teríamos duas etapas limitantes da formação de uma autonomia e criticidade do aluno: primeiro o Estado e depois o professor estariam fazendo a escolha pelo aluno por "uma Sociologia que seja verdadeiramente contestadora".

Essas expressões conduzem ao julgamento final que explicita como o autor vê a filiação das OCEM à política neoliberal: 
As DCNEM, os PCN's e as OCN's não propõem um posicionamento político que contradiga a ordem, divagam sobre os clichês como o de 'cidadania' e o de 'trabalho', mediante textos que apresentam uma linguagem erudita, e até poética, somente com a intenção de mascarar a contradições do projeto neoliberal de escola. A racionalidade orientadora dos textos é comprometida com a manutenção do status quo hegemônico (Ferreira, 2007, p. 50).

E conclui essa parte assumindo um posicionamento político definido: "Me apego à utopia e continuo achando possível a existência de uma escola que seja realmente humanista. Para isso, trata-se de ir além da sociedade regida pelo capital, e engendrar um projeto de sociedade verdadeiramente socialista" (Ferreira, 2007, p. 50).

Em que pese não haver uma definição clara do que seja uma escola humanista - poder-se-ia aventar a ideia de que seria uma escola com presença mais efetiva das Ciências Humanas, dentre elas a Sociologia, mas isso seria ainda uma confusão ou ignorância do que foi a presença das humanidades na escola, que estaria mais próximo da predominância das letras (literaturas) no currículo; em que pese não haver uma identidade entre humanismo e socialismo, e em certa medida os movimentos políticos denominados humanistas terem um caráter mais reformista do que revolucionário; propõe-se que no ensino desta "Sociologia verdadeiramente contestadora", "trata-se de ir além da sociedade regida pelo capital, e engendrar um projeto de sociedade verdadeiramente socialista". Ainda uma vez entendo que o Estado e o professor estariam subtraindo os meios de construção da autonomia dos alunos e subestimando sua capacidade de fazer as escolhas por si mesmos, desde que lhes fossem apresentados "[...] recursos teóricos [que a Sociologia tem] para envolver o educando num processo emancipatório", mas que o autor entende como de alcance limitado que "[...] não contribui com opções teóricas que realmente confrontam a realidade".

Mas onde será que essa utopia a que se apega o autor é possível? Tanto o artigo de Casão e Quinteiro quanto à monografia de Ferreira chegam ao mesmo lugar, que não é utopia, pois, de acordo com os textos, existe mesmo:

No Paraná, a SEED avança quanto à determinação de 'conteúdos estruturantes' que foram pensados com a ajuda dos professores da rede estadual durante os cursos de capacitação. [...] Outra iniciativa foi a elaboração do livro público de Sociologia pelos professores da rede estadual do Paraná, conferindo legitimidade à disciplina (Casão; Quinteiro, 2007, p. 236-237).

'As Diretrizes Curriculares para a Educação Pública do Estado do Paraná (2006) chegam às escolas como um documento oficial que traz as marcas de sua construção: a horizontalidade e polifonia'. Veja que essa apresentação, por si só, já demarca uma posição política mais democrá-

Educação \& Realidade, Porto Alegre, v. 39, n. 1, p. 17-38, jan./mar. 2014.

Disponível em: <http://www.ufrgs.br/edu_realidade> 
Ciência e Ideologia na Prática dos Professores de Sociologia no Ensino Médio

tica, se comparada aos outros documentos explanados nos tópicos anteriores. Pelo o que se tem registro, essas Diretrizes Estaduais contaram com o envolvimento de professores das escolas paranaenses junto aos Núcleos Regionais de Educação, através da realização de seminários e debates com intuito de construir uma base para o Ensino Médio no estado.

Por definição, esse é um 'documento que traz, em si, o chão da escola e traça estratégias que visam nortear o trabalho do professor e garantir a apropriação do conhecimento pelos estudantes da rede pública' (Paraná, 2006b, p. 10), propõe-se construir um documento orientador do currículo para toda a rede pública estadual paranaense. Nessas Diretrizes primou-se por dar ênfase na problematização das relações entre a ciência (no sentido acadêmico) e a disciplina escolar, o que no caso específico da Sociologia considero como indispensável.

De maneira inovadora, optou-se por apresentar os fundamentos teórico-metodológicos de cada disciplina, definindo quais devem ser os caminhos a serem seguidos e estabelecendo uma orientação para o tratamento dos conteúdos através de procedimentos metodológicos e referencial teórico. Desta maneira, definiu-se como eixo os conteúdos estruturantes e os específicos (Ferreira, 2007, p. 46).

Em Casão e Quinteiro (2007), como relativizar que os conteúdos estruturantes foram determinados pela SEED, e "pensados com a ajuda dos professores", mas "durante os cursos de capacitação?" Todos sabem que esses cursos têm forte traço dirigista, pois são de capacitação e são realizados sob a coordenação de órgãos oficiais.

Quanto a Ferreira, devemos destacar certas expressões que aparecem no texto, quer como intervenção do autor, dando legitimidade ao documento oficial - "o que no caso específico da Sociologia considero como indispensável" - ou supervalorizando-o - "De maneira inovadora, optou-se por apresentar os fundamentos teórico-metodológicos de cada disciplina" -, quer como assunção de que o documento diz a verdade - “[...] um documento oficial que traz as marcas de sua construção: a horizontalidade e polifonia'. Veja que essa apresentação, por si só, já demarca uma posição política mais democrática, se comparada aos outros documentos explanados nos tópicos anteriores" -, e uma indistinção, num continuum, entre a fala do autor e a fala oficial - "Por definição, esse é um 'documento que traz, em si, o chão da escola e traça estratégias que visam nortear o trabalho do professor e garantir a apropriação do conhecimento pelos estudantes da rede pública' (Paraná, 2006b, p. 10)".

Um terceiro caso é o de Moraes (2011), em que a autora critica uma possível contradição existente no texto das OCEM, em que os autores "seguem para um novo posicionamento quanto ao papel da sociologia 
no contexto educacional. Não só como formadora de cidadãos, quanto também não completamente voltada para o objetivo de incentivar a críti$c a$, de acordo com as ideias deste documento" (Moraes, 2011, p. 6, grifo meu).

A questão aqui é a compreensão do que seja crítica ou qual a sua profundidade ou efetividade, pois entende a autora que nas OCEM nega-se essa possibilidade, quando dizem que,

[...] além dessa justificativa que se tornou slogan ou clichê
- 'formar o cidadão crítico' -, entende-se que haja outras
mais objetivas decorrentes da concretude com que a So-
ciologia pode contribuir para a formação do jovem bra-
sileiro: quer aproximando esse jovem de uma linguagem
especial que a Sociologia oferece, quer sistematizando
os debates em torno de temas de importância dados pela
tradição ou pela contemporaneidade (Brasil, 2006, p. 105).

Ora, o que se quis dizer é que a expressão formar o cidadão crítico assumiu um caráter retórico - no sentido de vazio -, apenas cumprindo um papel do que se poderia dizer politicamente correto ou de bom tom pedagógico-progressista, bastante encontradiço e obrigatório para quem escreve tais documentos no após-ditadura militar, mas sem maiores consequências. Assim, a contradição estaria entre tomar a formação crítica como clichê ou slogan e "demonstrar que a sociologia em sala de aula pode se basear em explicitar as formas de organização da sociedade moderna, revelando os processos de transformação e as condições sociais que dão continuidade ao sistema vigente" (Moraes, 2011, p. 6), pois "Incentivar a desnaturalização e o estranhamento significa implicitamente estimular os alunos à crítica do seu próprio meio social" (Moraes, 2011, p. 7, grifos da autora). E acrescenta:

Não há como, “observando as teorias sociológicas, compreender os elementos da argumentação - lógicos e empíricos - que justificam um modo de ser de uma sociedade, classe, grupo social e mesmo comunidade" (MEC, 2006, p. 105) sem perceber as contradições internas da organização desta mesma sociedade e sem ambicionar a sua transformação. Sendo assim, a crítica se torna inevitável (Moraes, 2011, p. 7).

Aqui se explicita a divergência de compreensão do que é crítica. Nas OCEM: "[...] observando as teorias sociológicas, compreender os elementos da argumentação - lógicos e empíricos - que justificam um modo de ser de uma sociedade, classe, grupo social e mesmo comunidade" (Brasil, 2006, p. 105). Para autora, é "perceber as contradições internas da organização desta mesma sociedade e ambicionar a sua transformação. Sendo assim, a crítica se torna inevitável” (Moraes, 2011, p. 7). E, para se afirmar, recorre ao argumento de autoridade dado por Paulo Freire: “[...] consciência e mundo não podem ser entendidos separadamente, dicotomizadamente, mas em suas relações contraditó- 
Ciência e Ideologia na Prática dos Professores de Sociologia no Ensino Médio

rias. Nem a consciência é a fazedora arbitrária do mundo, da objetividade, nem dele puro reflexo" (Freire, 2001 apud Moraes, 2011, p. 9).

Sem entrar no debate sobre as ideias pedagógicas de Paulo Freire, quer por seu caráter efetivamente antinômico - consciência e mundo não podem ser entendidos separadamente, dicotomizadamente-, quer pelo seu caráter ostensivamente metafísico - consciência e mundo podem ser entendidos em suas relações contraditórias -, é necessário dizer que há uma considerável distância entre pensamento e ação, tal qual entre "perceber as contradições internas da organização desta mesma sociedade e ambicionar a sua transformação". O problema ainda é dado pela $11^{\text {a }}$ Tese sobre Feuerbach proposta por Marx - "Os filósofos se limitaram a interpretar o mundo diferentemente, cabe transformá-lo" -, o que parece se impor a todos, mas a muitos acriticamente.

Como disse noutro lugar, a respeito das pesquisas e debates sobre ensino de Sociologia,

Outra característica comum nessa tradição tem sido o tom pessoal com que se conduzem os debates e a pesquisa sobre o tema. Também não é possível separar sujeito e objeto porque são sempre professores envolvidos com o ensino de sociologia, não se caracterizando essa pesquisa apenas como um trabalho de coleta, análise e interpretação de dados. Por outro lado, às vezes a situação chega a tal ponto que a necessidade de intervenção aparece como a causa motora principal para tantos abandonarem suas atividades reconhecidas como mais acadêmicas e lançarem-se em tal tarefa [...] (Moraes, 2003, p. 6).

\section{A Terceira Via: volta aos clássicos}

Em sua pesquisa sobre professores da rede pública do Distrito Federal, Mario Bispo Santos (2002) constata a diferença de concepção entre os professores formados em Ciências Sociais e os formados em outras áreas (Pedagogia, História, Geografia, Filosofia): os formados em Ciências Sociais tendem a compreender o ensino de Sociologia a partir de uma visão científica ou de seu potencial cognitivo - conceitos, teorias - que permitiria aos alunos a compreensão dos fundamentos da vida social, das relações sociais, entendendo-a como uma disciplina teórica; enquanto que os formados em áreas afins lhe dão um caráter mais instrumental, sobretudo visando à ação, entendendo-a como uma disciplina prática. E é interessante notar que, quando se pensa em pesquisa como um recurso de ensino de Sociologia, os professores formados em Ciências Sociais resistem a esse recurso por entenderem que é impossível trabalhar a pesquisa no nível médio, fugindo aos rigores de uma pesquisa sociológica, enquanto que os outros professores concebem a possibilidade de uso de instrumentais científicos com seus alunos, independentemente do caráter menos rigoroso das pesquisas que propõem (Santos, 2002). 
Pois bem, essas são questões que temos de enfrentar quando pensamos no ensino de Sociologia e que estão diretamente relacionadas com formação do professor. Embora na pesquisa de Santos se possam distinguir tão claramente os grupos, persiste do lado de cá - formadores de professores e professores de Sociologia no ensino médio -, assim como do lado de lá - os assim chamados formadores de opinião, jornalistas polifônicos e multidisciplinares -, uma discussão sobre os limites e as conveniências de se ensinar visando à formação científica dos alunos ou a sua conscientização (política). Enquanto para uns o temor se dá em vista de se preservar e garantir o rigor e a legitimidade das Ciências Sociais, transformadas no recorte disciplinar Sociologia; para outros, o temor é que se vá doutrinar jovens e crianças com uma ideologia esquerdizante, incutindo-lhes o "exotismo da luta de classes", como dizia Getúlio às vésperas do golpe de 10 de novembro de 1937 (ou “a guerra de classes", como diz o economista Roberto Macedo, no artigo citado). Ficamos então imobilizados por uma pretensa neutralidade das Ciências (Sociais) ou enfrentamos e superamos esse falso dilema? Como alternativa, emprestamos do campo das Ciências Naturais uma ideia que há décadas vem fazendo frutos no ensino dessas ciências na escola média, a alfabetização científica (Chassot, 2003), que se entende como o domínio de métodos, linguagem, cânones e controvérsias de um campo científico, que no caso das Ciências Sociais e a disciplina escolar correspondente - a Sociologia - trata-se de observar "[...] as teorias sociológicas, compreender os elementos da argumentação-lógicos e empíricos - que justificam um modo de ser de uma sociedade, classe, grupo social e mesmo comunidade" (Brasil, 2006, p. 105).

Retomemos, para nos inspirar, as palavras de Antônio Candido a respeito da criação da Faculdade de Filosofia da USP e do curso de Ciências Sociais:

Acostumados a falar em 'sociologia burguesa' e conceituando de maneira por vezes estreita o pensamento revolucionário, muitos intelectuais deixam de perceber a força progressista que as Ciências Humanas representaram numa sociedade atrasada, como era a brasileira dos anos 30 e 40, pelo simples fato de serem modos objetivos e sistemáticos de descrever a realidade. Por isso mesmo a Sociologia foi tão combatida pela direita e apresentada como perigo para a tradição (Candido, 2011, p. 233).

Nesta passagem, Antônio Candido apresenta o duplo sentido radical de criticidade da Sociologia: por um lado, por serem "modos objetivos e sistemáticos de descrever a realidade” e, por outro, e por isso mesmo, pela "força progressista que as Ciências Humanas representaram numa sociedade atrasada, como era a brasileira dos anos 30 e 40" - o que podemos resumir na fórmula ciência e consciência.

Outra não era visão de Durkheim sobre o papel da Sociologia da Educação como disciplina dos cursos de formação de professores na França do começo do século XX:

Educação \& Realidade, Porto Alegre, v. 39, n. 1, p. 17-38, jan./mar. 2014.

Disponível em: <http://www.ufrgs.br/edu_realidade> 
Ciência e Ideologia na Prática dos Professores de Sociologia no Ensino Médio

[...] o mais urgente é ajudar os futuros professores de nossos institutos a fazer-se coletivamente uma opinião sobre o que deve ser o ensino do qual são responsáveis, os fins que devem perseguir, os métodos que devem empregar. Pois bem, para isto não há outra forma senão pô-los em presença dos problemas que se colocam e das razões pelas quais se colocam, de pôr-lhes nas mãos todos os elementos de informações que possam ajudá-los a resolver estes problemas, que possam guiar suas reflexões pela via de um ensino livre... (Durkheim, 1938 apud Baudelot, 1991, p. 29).

Esta era a dupla militância de um autor que estamos muitas vezes acostumados a ver como conservador: "[...] homem de ciência, preocupado em analisar objetivamente a realidade social, com base nos fatos" (Baudelot, 1991, p. 30), sentia-se "afetado pela evolução e transformação da sociedade na qual vivia" (Baudelot, 1991, p. 30) e entendia que "[...] a Sociologia que edificava só tinha para ele sentido se pudesse contribuir, iluminando-a, para esta mudança social" (Baudelot, 1991, p. 30). Para Durkheim, “[...] nossas especulações não merecem uma hora de esforço se não têm mais que um interesse especulativo" (1938 apud Baudelot, 1991, p. 30).

Quase numa paráfrase, encontramos fala de Bourdieu a respeito da Sociologia, que tem nos servido a todos, quando pensamos no ensino da disciplina no nível médio, e dela podemos extrair as mesmas consequências: "A Sociologia não valeria nem uma hora de esforços se fosse um saber de especialista reservado aos especialistas" (Bourdieu, 1989, p. 58). Para além de uma pretensa neutralidade científica, o que encontramos é uma relação profunda e necessária entre fazer ciência social e viver numa realidade social, entre conhecer e intervir. No entanto essa percepção não é dada imediatamente, e a mesma Sociologia é o meio pelo qual chegamos a esta consciência do fazer ciência: "Só a sociologia da sociologia - e do sociólogo - pode dar um certo domínio dos fins sociais que podem estar na mira dos fins científicos diretamente perseguidos" (Bourdieu, 1989, p. 58).

Em Ciência como Vocação, Weber apresenta as contribuições da ciência "para a vida prática e pessoal". Primeiramente, a ciência coloca "[...] a nossa disposição certo número de conhecimentos que nos permitem dominar tecnicamente a vida por meio da previsão" (1983, p. 45). Em segundo lugar, nos fornece "métodos de pensamento, isto é, os instrumentos e uma disciplina" (Weber, 1983, p. 45). E, em terceiro lugar, "a ciência contribui com a clareza" (Weber, 1983, p. 45). No entanto afirma que muitas vezes, diante de questões de valores, isto é, a adequação entre fins e meios, há que se fazer escolhas, e aí "[...] o professor só pode mostrar a necessidade da escolha, mas não pode ir além, caso se limite ao papel de professor e não queira transformar-se em demagogo" (Weber, 1983, p. 45).

O professor, tal como o cientista discutido por Weber, “[...] pode esclarecer que determinada posição deriva de uma e não de outra con- 
cepção" (1983, p. 46), pois, se não há ciência sem pressupostos, o professor não tem o direito de apresentar qualquer teoria sem esclarecer suas origens, seus compromissos e interesses. Esta é a obra do professor que assim se põe "[...] a serviço do dever de brotarem, nas almas alheias, a clareza e o sentido de responsabilidade. [...] e lhe será tanto mais fácil realizar essa obra quanto mais ele evite, escrupulosamente, impor ou sugerir, à audiência, uma convicção” (Weber, 1983, p. 46).

Mas, então, como Weber vê a prática leal do professor? O autor refere-se explicitamente ao professor universitário, mas creio que se possa aplicar o mesmo modus operandi, tanto mais ainda, ao professor da escola básica. Ele diz:

Quando em um curso universitário, manifesta-se a intenção de estudar, por exemplo, a 'democracia', procede-se ao exame de suas diversas formas, o funcionamento próprio de cada uma delas e indaga-se das consequências que uma e outra acarretam; em seguida, opõe-se à democracia as formas não democráticas da ordem política e tentase levar essa análise até a medida em que o próprio ouvinte se ache em condições de encontrar o ponto a partir do qual poderá tomar posição, em função de seus ideais básicos. O verdadeiro professor se impedirá de impor, do alto de sua cátedra, uma tomada de posição qualquer, seja abertamente, seja por sugestão [...] (Weber, 1983, p. 39).

\section{À Guisa de Conclusão}

Parece que as duas primeiras concepções assumem perspectivas claramente ideológicas ao defenderem a ausência ou a presença da Sociologia no currículo do ensino médio a partir de posicionamentos políticos não críticos. A primeira, situada à direita no espectro ideológico porque assume um ponto de vista conservador e preconceituoso, vê o currículo como lugar da tradição - predominância das disciplinas tradicionais - e considera sociologia e socialismo a mesma coisa. A segunda, situada à esquerda, nem por isso é mais crítica, pois fundamenta-se na crença de que a escolha de uma concepção de mundo - o marxismo pode recobrir todo o debate que o campo das Ciências Sociais abrange e que é o bastante para ser ensinado. Por outro lado, são perspectivas autoritárias e manipuladoras. A da mídia, por confundir deliberadamente as funções de expressar e de formar a opinião pública - dizendo-se expressar, pretende formar, pretendendo formar, tenta impor sua opinião privada como se fosse a opinião pública, essa entidade metafísica (Moraes, 1991). A que assume um posicionamento político por antecipar o produto ao processo, antes de contribuir para a emancipação dos alunos, pretende “[...] engendrar um projeto de sociedade verdadeiramente socialista”.

O debate sobre o ensino de Sociologia sempre esteve envolvido por tensões ideológicas. Por um lado, se aceita e se reforça uma possível

Educação \& Realidade, Porto Alegre, v. 39, n. 1, p. 17-38, jan./mar. 2014.

Disponível em: <http://www.ufrgs.br/edu_realidade> 
caracterização ideológica da disciplina, ignorando as tensões internas às Ciências Sociais e à ciência Sociologia, e mesmo que a disciplina escolar até os anos 1940 tendia mais para uma concepção conservadora, de controle social, do que de emancipação e crítica. Com isso há uma tendência de se pensar a disciplina Sociologia - a escolha de conteúdos, por exemplo - a partir de uma preocupação ideológica, marcada pelas propostas de conscientização e intervenção na realidade. Por outro lado, isso reforça elementos que dão azo à crítica conservadora, ao dizer que o ensino de Sociologia visa antes de tudo à manipulação dos alunos, na verdade nem existindo propriamente ensino, senão doutrinação. Já uma concepção menos engajada e mais formativa, de tratamento dos princípios epistemológicos e procedimentos científicos das Ciências Sociais, ou da discussão sobre elaboração de modelos teóricos, ou mesmo sobre a construção conceitual nestas ciências - a que chamamos alfabetização científica -, é condenada a partir de um posicionamento pseudocrítico a certa perspectiva de neutralidade e objetividade que essa concepção encerraria. Ou deliberadamente ignorada por aqueles que querem caracterizar a disciplina sempre como doutrinação barata ou molestamento ideológico explícito.

Certamente essa terceira via que apresento pode ser vista - até por conta de alguns dos autores citados - com um caráter ideológico à direita, por conta de uma defesa do que os críticos de Weber chamam de uma "pretensa neutralidade axiológica", por isso a necessidade de explicitar o posicionamento, e o posicionamento deve ser por uma "Sociologia como um instrumento de crítica e de intervenção nas políticas da educação", "uma Sociologia que seja verdadeiramente contestadora”. Mas como negar o caráter crítico profundo do que dizem Antônio Candido ("[...] a força progressista que as Ciências Humanas representaram numa sociedade atrasada, como era a brasileira dos anos 30 e 40, pelo simples fato de serem modos objetivos e sistemáticos de descrever a realidade”), Durkheim (“[...] o mais urgente é ajudar os futuros professores de nossos institutos [...], pô-los em presença dos problemas que se colocam e das razões pelas quais se colocam, de pôr-lhes nas mãos todos os elementos de informações que possam ajudá-los a resolver estes problemas, que possam guiar suas reflexões pela via de um ensino livre [...]"), Bourdieu ("Só a sociologia da sociologia - e do sociólogo - pode dar um certo domínio dos fins sociais que podem estar na mira dos fins científicos diretamente perseguidos”) e Weber (“[...] tenta-se levar essa análise até a medida em que o próprio ouvinte se ache em condições de encontrar o ponto a partir do qual poderá tomar posição, em função de seus ideais básicos”)?

Reitero aqui o que disse na introdução. Entendo a escola pública ainda como espaço de transição para o mundo político, visto que se situa entre a família - âmbito privado por excelência - e a sociedade civil esfera caracteristicamente política -, e o professor como agente público a quem cabe a formação de crianças (e jovens), conforme diz Arendt: 
Normalmente a criança é introduzida ao mundo pela primeira vez através da escola. No entanto, a escola não é de modo algum o mundo e não deve fingir sê-lo; ela é, em vez disso, a instituição que interpomos entre o domínio privado do lar e o mundo com o fito de fazer com que seja possível a transição, de alguma forma, da família para o mundo. Aqui, o comparecimento não é exigido pela família, e sim pelo Estado, isto é, o mundo público, e assim, em relação à criança, a escola representa em certo sentido o mundo, embora não seja o mundo de fato (2007, p. 238).

Assim, as escolhas feitas pelo professor devem ser norteadas pela responsabilidade, superando em sala de aula as suas convicções pessoais em favor da construção da autonomia dos alunos (Weber, 1983); e mesmo mantendo-se nos limites do que se tem chamado de alfabetização científica (scientific literacy) - algo praticado há décadas na área das ciências naturais -, o ensino de Sociologia cumpriria um importante e necessário papel na educação básica, fazendo diferença.

Recebido em 06 de março de 2013

Aprovado em 08 de julho de 2013

\section{Referências}

ARENDT, Hannah. A Crise da Educação. In: ARENDT, Hannah. Entre o Passado e o Futuro. São Paulo: Perspectiva, 2007.

ASCHER, Nelson. Doutrinação Barata. Folha de S. Paulo, Folha Ilustrada, v. 88, n. 28, 922, p. E6, 9 jun. 2008.

AZEVEDO, Reinaldo. Cuidem de suas crianças! Os molestadores ideológicos vêm aí. Blog da Veja.com, 3 jun. 2008. Disponível em: < http://veja.abril.com.br/ blog/reinaldo/geral/cuidem-suas-criancas-os-molestadores-ideologicos-vemai >. Acesso em: 2 jan. 2014.

BASTIDE, Paul Arbousse; COELHO, Ruy. O Brasil Escapa às Soluções Simplistas. O Estado de S. Paulo, São Paulo, v. 100, n. 32.082, p. 133, 180, 14 out. 1979. Série Documento/Universidade.

BAUDELOT, Christian. A Sociologia da Educação: para quê? Teoria e Educação, Porto Alegre, n. 3, 1991.

BOURDIEU, Pierre. O Poder Simbólico II: introdução a uma sociologia reflexiva. Lisboa; Rio de Janeiro: Difel, 1989.

BRASIL. Ministério da Educação. Orientações Curriculares para o Ensino Médio: conhecimentos de Sociologia. Brasília: MEC; DPEM, 2006.

CANDIDO, Antônio. A Faculdade no Centenário da Abolição. In: CANDIDO, Antônio. Vários Escritos. 5. ed. São Paulo: Duas Cidades, 2011. P. 229-241.

CASÃO, Carolina Dias Cunha; QUINTEIRO, Cristiane Thaís. Pensando a Sociologia no Ensino Médio através dos PCNEM e das OCNEM. Revista Mediações, Londrina, v. 12, n. 1, p. 225-238, 2007.

CHASSOT, Attico. Alfabetização Científica: uma possibilidade para a inclusão social. Revista Brasileira de Educação, Rio de Janeiro, n. 22, p. 89-100, jan./abr. 2003.

Educação \& Realidade, Porto Alegre, v. 39, n. 1, p. 17-38, jan./mar. 2014.

Disponível em: <http://www.ufrgs.br/edu_realidade> 
Ciência e Ideologia na Prática dos Professores de Sociologia no Ensino Médio

FERREIRA, Eduardo Carvalho. Os Lugares da Sociologia no Ensino Médio: o caso da cidade de Londrina - PR (2007). Monografia (Graduação em Ciências Sociais) - Departamento de Ciências Sociais, Universidade Estadual de Londrina, Londrina, 2007.

IOSCHPE, Gustavo. Errar é humanas. Veja.com/Educação, 30 jun. 2008, Disponível em: <http://veja.abril.com.br/gustavo_ioschpe/notas_300608.shtml>. Acesso em: 2 jan. 2014.

KAUFMANN, Felix. Metodologia das Ciências Sociais. Rio de Janeiro: Francisco Alves, 1977.

MACEDO, Roberto. Sociologia \& Cia. no CNE \& Cia. O Estado de S. Paulo, São Paulo, v. 127, n. 41.183, p. 2, 20 jul. 2006.

MORAES, Amaury Cesar. Imprensa e Constituinte: o projeto político do jornal O Estado de S. Paulo (1986-1988). 1991. Dissertação (Mestrado em Ciência Política) - Faculdade de Filosofia, Letras e Ciências Humanas, Universidade de São Paulo, São Paulo, 1991.

MORAES, Amaury Cesar. Licenciatura em Ciências Sociais e Ensino de Sociologia: entre o relato e o balanço. Tempo Social, São Paulo, Universidade de São Paulo, v. 15, n. 1, p. 5-20, maio 2003.

MORAES, Amaury Cesar. O Veto de FHC: o sentido de um gesto. In: CARVALHO, Lejeune Mato Grosso (Org.). Sociologia e Ensino em Debate. Ijuí: Ed. Unijuí, 2004. P. 105-111.

MORAES, Larissa Messias. Desafios e Propostas da Sociologia no Ensino Médio à luz da Didática para a Pedagogia Histórico-Crítica de João Luiz Gasparin. In: ENCONTRO ESTADUAL DE DIDÁTICA E PRÁTICA DE ENSINO, 4., 2011, Goiânia. Anais... Goiânia: UFG, 2011. Disponível em: <http://www.ceped.ueg.br/ anais/ivedipe/pdfs/sociologia/co/361-786-1-SM.pdf>. Acesso em: 17 out. 2012.

SANTOS, Mário Bispo. A Sociologia no Ensino Médio: o que pensam os professores da rede pública do Distrito Federal. 2002. Dissertação (Mestrado em Sociologia) - Instituto de Ciências Sociais, Universidade de Brasília, Brasília, 2002.

SCHWARTSMAN, Hélio. A Volta da Filosofia. Folha Online. 12 jun. 2008. Disponível em: <http://wwwl.folha.uol.com.br/folha/pensata/helioschwartsman/ ult510u411269.shtml>. Acesso em: 2 jan. 2014 .

WEBER, Max. A Ciência como Vocação. In: WEBER, Max. Ciência e Política: duas vocações. Brasília: Ed. UnB/São Paulo: Cultrix, 1983. P. 15-52.

Amaury Cesar de Moraes é graduado em Ciências Sociais e Filosofia pela Universidade de São Paulo (USP), onde fez também o mestrado (Ciência Política) e o doutorado (Educação). Coordenou a equipe que elaborou as Orientações Curriculares para o Ensino Médio-Sociologia, participando da campanha pela obrigatoriedade da disciplina no Ensino Médio. Autor de vários artigos sobre o ensino de Sociologia, é professor de Metodologia do Ensino de Ciências Sociais na Faculdade de Educação da USP.

E-mail: acmoraes@usp.br 